\title{
Experimental measurement of particle size effects on the self-heating ignition of biomass: homogeneous samples of dust and pellets
}

\author{
Francesco Restuccia $^{\mathrm{a}}$, Nieves Fernandez-Anez ${ }^{\mathrm{b}}$, Guillermo Rein $^{\mathrm{a}, *}$ \\ ${ }^{a}$ Mechanical Engineering Imperial College London, SW7 2AZ, UK \\ ${ }^{b}$ Department of Fire Safety and HSE Engineering, Western Norway University of Applied Sciences, Haugesund, Norway
}

\begin{abstract}
Biomass can become an important fuel source for future power generation worldwide. However biomass piles are prone to self-heating and can lead to fire. When storing and transporting biomass, it is usually in the form of pellets which vary in diameter but are on average in the order of $7 \mathrm{~mm}$. However, pellets tend to break up into smaller particles and into dust down to the $\mu \mathrm{m}$ size. For self-heating, size of particles is known to matter but the topic is poorly studied for biomass piles. This work presents an experimental study on the self-heating ignition behaviour of different particle sizes of wheat biomass. We study for the first time homogeneous samples from the dust scale to pellet diameter size, ranging from diameters of $300 \mu \mathrm{m}$ to $6.5 \mathrm{~mm}$. Experiments are done in an isothermal oven to find minimum ignition temperatures as a function of sample volume. The results are analysed using Frank-Kamenetskii theory. For the homogeneous biomass samples studied, we show that particle diameter variation does not bring a large change in self-heating ignition behaviour. The present work can be used to help quantify size effects on biomass ignition and help address the safety problems of biomass fires.
\end{abstract}

Keywords:

self-heating ignition, biomass, particle size effects, Frank-Kamenetskii theory

\section{Introduction}

In the current era, different fuel options are being studied to shift away from the traditional fossil fuel energy market, driven by a need to reduce carbon emissions. This has brought on the development of many protocols and regulations worldwide. The European Union member states are working towards 202020 targets, establishing that by the year 2020 greenhouse gas emissions should be reduced by $20 \%$, renewable energy should represent $20 \%$ of the European final energy consumption, and energy efficiency should increase by $20 \%$ [1]. The role of biomass as an alternative energy source becomes crucial to achieve these targets.

Biomass presents heterogeneous properties that require extensive characterisation because of its natural origin and considerable variation with source. One of the fuel characteristics that is particularly important for safety and fire hazards is the ignition tendency of the materials. Most of these fuels come in bulk, but produce particles of many sizes all the way down to dust by abrasion or friction during their handling. The effect of small particles and dust has to be taken into account as their behaviour can be considerably different from that of large particles. The demarcation from small particle to dust size is not well defined, but in practice any solid particle with a particle diameter of less than $500 \mu \mathrm{m}$ is considered dust [2].

The physical and chemical characteristics of the sample can impact the tendency of the material to ignite. Focusing on particle size, some work has been done on the flammability of several solid fuels studying its influence on the minimum explosion concentration, minimum ignition energy and minimum ignition temperature [3,4]. However none of this work focused on self-heating ignition.

\footnotetext{
${ }^{*}$ Corresponding author: G. Rein

Email address: g.rein@imperial.ac.uk (Guillermo Rein)
} 
One of the most dangerous processes associated with dust and pellet stockpiles is the risk of fires. These fires can be caused by self-heating ignition. Self-heating ignition is defined as the tendency a porous solid fuel has to undergo spontaneous exothermic reactions in oxidative atmospheres at low temperatures [5, 6]. Knowledge of the tendency of materials to self-ignite is essential to power plants that handle, store, or process biomass resources [7]. Critical conditions for self-heating in stored bulk materials could be determined with laboratory-scale methods such as adiabatic calorimetry, hot plate experiments and isothermal oven tests [5, 8-13]. The influence of particle size on the storage of materials has to consider the following two countering properties: When the particle size increases, the gaps between the particles with oxidizer present increase, so self-heating ignition becomes easier since oxidation is promoted. But on the other hand, air is less conductive than the material, decreasing the heat transfer and therefore the chance of self-heating ignition [14].

For self-heating, the reactivity of coal is proportional to the average surface area to volume ratio of the sample, A/V, with a decreasing particle size corresponding to an increase in the reactivity and propensity to self-heating ignition $[15,16]$. As biomass comes in different sizes and shapes, the existing literature on self-heating ignition of biomass is not carried out at one uniform size. It is often assumed that the particle size plays an important role on self-heating ignition conditions, but there is no experimental quantification of this influence in the literature for diameters greater than dust diameters. Some work has been previously carried out to determine the self-heating ignition characteristics of biomass with constant particle size [7, 8, 17, 18] and dust layers [19-21]. This work aims to fill these literature gaps by experimentally studying for the first time the self-heating ignition properties of 4 different homogeneous particle size ranges to quantify the different self-heating characteristics of wheat biomass with varying particle size.

\section{Experimental methodology}

To carry out this experimental work on self-heating ignition we use wheat biomass particles. The reason for choosing wheat biomass is that its physical properties are well characterised and is a material commonly used for power generation, and therefore have detailed elemental and physical parameters such as the thermal conductivity which allow the extraction of more thermal and kinetic parameters from the experimental data reported in this paper. The biomass was in the form of pellets made of compressed wheat with varying sizes between $2.6 \mathrm{~mm}$ diameter and $6.5 \mathrm{~mm}$ diameter. The pellets were grinded using a hand blender and separated into different size distributions using mechanical sieves. A series of 4 particle size distributions was produced based on particle diameter. The first was made of unground pellets, of diameter between $6.5 \mathrm{~mm}$ and $2.6 \mathrm{~mm}$ (coarse particles). The second were particles with a diameter distribution between $2.6 \mathrm{~mm}$ and $2 \mathrm{~mm}$ (medium particles), the third between $2 \mathrm{~mm}$ and $1 \mathrm{~mm}$ (fine particles), and the fourth between $1 \mathrm{~mm}$ and $300 \mu \mathrm{m}$ (dust). These distributions span particle sizes from pellet size all the way to dust size. These sample distribution sets are presented in Fig. 1. Elemental analysis was carried out for the wheat, resulting in $42.66 \% \mathrm{C}, 6.20 \% \mathrm{H}$, and $0.39 \% \mathrm{~N}$.

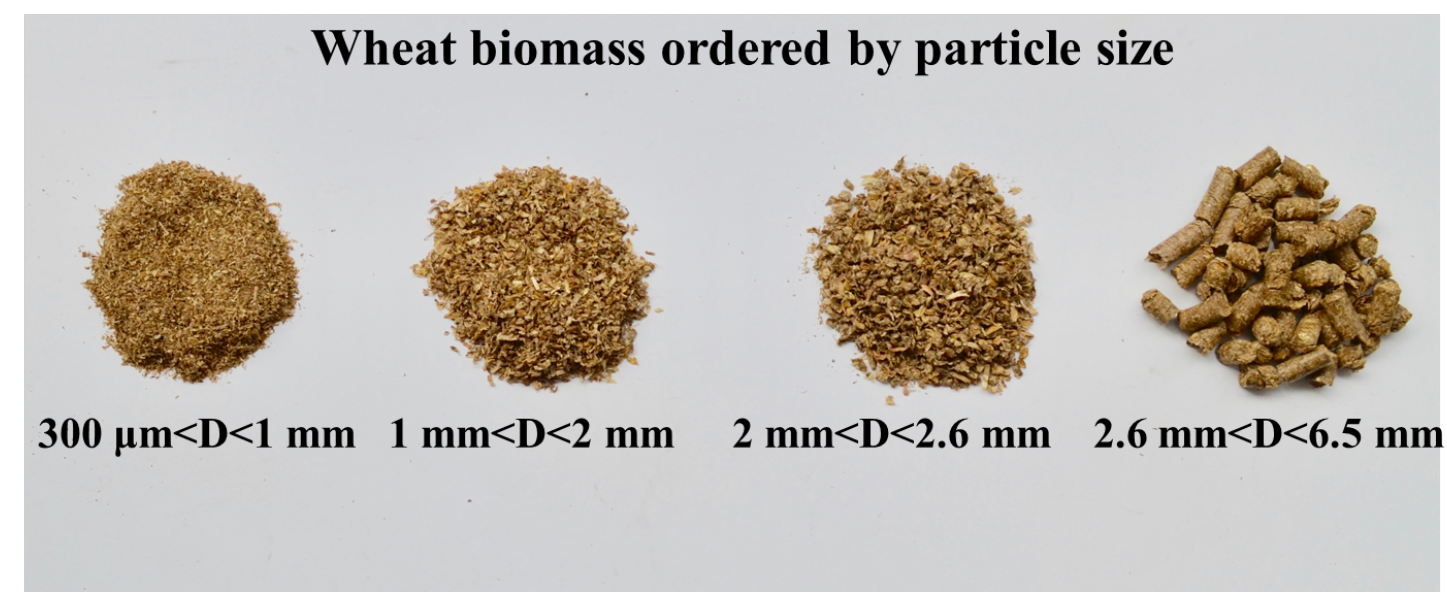

Figure 1: Different sample size wheat biomass, ordered from left to right by increasing particle size. 
These particle size distributions were individually studied to determine the minimum critical ambient temperature for self-heating, $T_{a, c}$, that leads to self-ignition. A laboratory setup composed of an isothermal oven was constructed based on the British Standards EN 15188:2007 and previous work by Bowes [5], and three differently sized cubic shaped wire mesh baskets were used to study the particle size effect on ignition. The cube shape was chosen for the baskets as it is the easiest shape with which to increase geometry size in a rectangular oven without making the larger samples approach the oven walls. The baskets were made of $0.5 \mathrm{~mm}$ diameter wire mesh with volumes of 131,442 and $1049 \mathrm{~cm}^{3}$. Different sized baskets were used because as the basket volume increases the critical ignition temperature decreases since the ratio of heat losses to the environment to heat generated by chemical reactions decreases, as well as the critical ignition temperature [22]. Each sample was placed in a basket at the centre of the bottom surface of an isothermal oven heated to a given uniform ambient temperature, $T_{a}$. The bottom surface of the oven was not in contact with any of the oven heating element and was at the same constant temperature as it's surrounding air. The oven had forced air circulation to prevent temperature stratification and provide sufficient oxygen supply. The forced air circulation rate required was controlled by a fan of adjustable speed and was set to ensure that the measured temperature difference between the top and bottom of oven was below $2^{\circ} \mathrm{C}$. To limit the influence of the forced flow, a large mesh cage was placed around the sample. A diagram of the setup is presented in Fig. 2. The temperature inside the sample was monitored using two thermocouples placed at the centre of the sample $0.5 \mathrm{~cm}$ apart. Oven temperature was also measured by a thermocouple placed several centimeters away from the basket, inside the mesh cage, in the vertical middle plane of the oven. If the sample failed to reach ignition the experiment was repeated with a fresh sample at a higher temperature. If the sample reached ignition, then the experiment was repeated with a fresh sample at a lower temperature. The experiments were carried out until $T_{a, c}$ for ignition was located within $\pm 2.5^{\circ} \mathrm{C}$ for each tested particle size. At least two experiments were conducted at each particle size and basket volume condition. This experimental setup is the same as the one used in [11-13]. A summary of the experiments carried out is presented in Table 1.

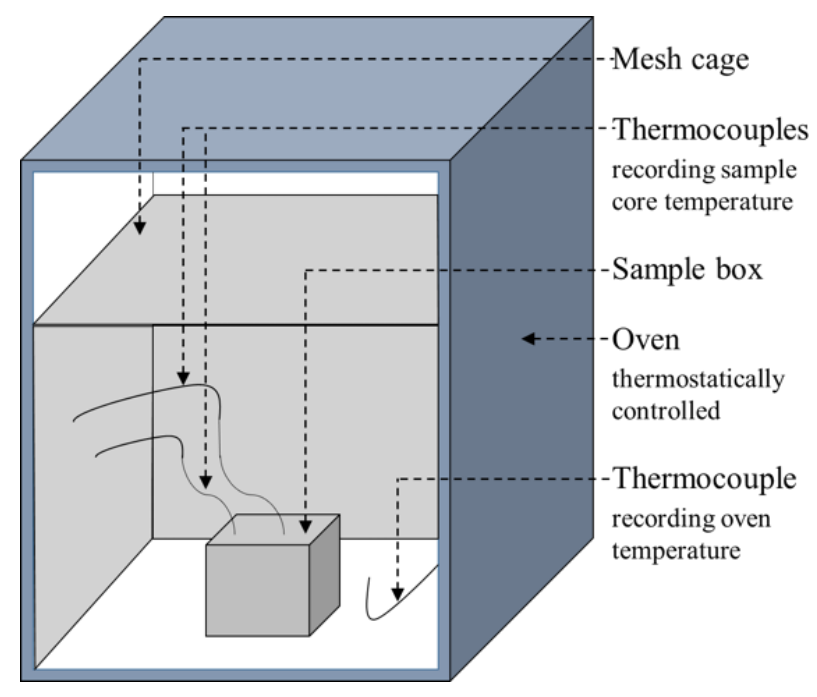

Figure 2: Experimental setup for self-heating measurements, same as used in [11-13].

Table 1: Number of experiments carried out for each particle distribution range of wheat biomass.

\begin{tabular}{lccc}
\hline particle distribution size & \multicolumn{3}{c}{ Basket volume } \\
& $131 \mathrm{~cm}^{3}$ & $442 \mathrm{~cm}^{3}$ & $1049 \mathrm{~cm}^{3}$ \\
\hline Pellets, $2.6 \mathrm{~mm}<\mathrm{D}<6.5 \mathrm{~mm}$ (coarse) & 2 & 2 & 2 \\
$2 \mathrm{~mm}<\mathrm{D}<2.6 \mathrm{~mm}$ (medium) & 2 & 2 & 2 \\
$1 \mathrm{~mm}<\mathrm{D}<2 \mathrm{~mm}$ (fine) & 3 & 3 & 3 \\
$300 \mu \mathrm{m}<\mathrm{D}<1 \mathrm{~mm}$ (dust) & 3 & 2 & 3 \\
\hline
\end{tabular}


The bulk density found when using these materials in basket experiments for the different particle size distributions is presented in Fig. 3. It is clear from the figure that the particles below $2.6 \mathrm{~mm}$ diameter all have similar bulk densities, while the pellets have a higher density, due to the fact that they are produced by compressing wheat. The thermal conductivity of the wheat pellets was measured experimentally using a guarded heat flow meter and was found to be $0.1715 \mathrm{~W} / \mathrm{mK}$ at $165{ }^{\circ} \mathrm{C}$. This temperature chosen for the conductivity value is based on the range of temperatures measured in this experimental work. Previous work has shown that thermal conductivity differences are less than $10 \%$ between coarse and fine particles of biomass [23], so this measured value was used for all the particle size distributions.

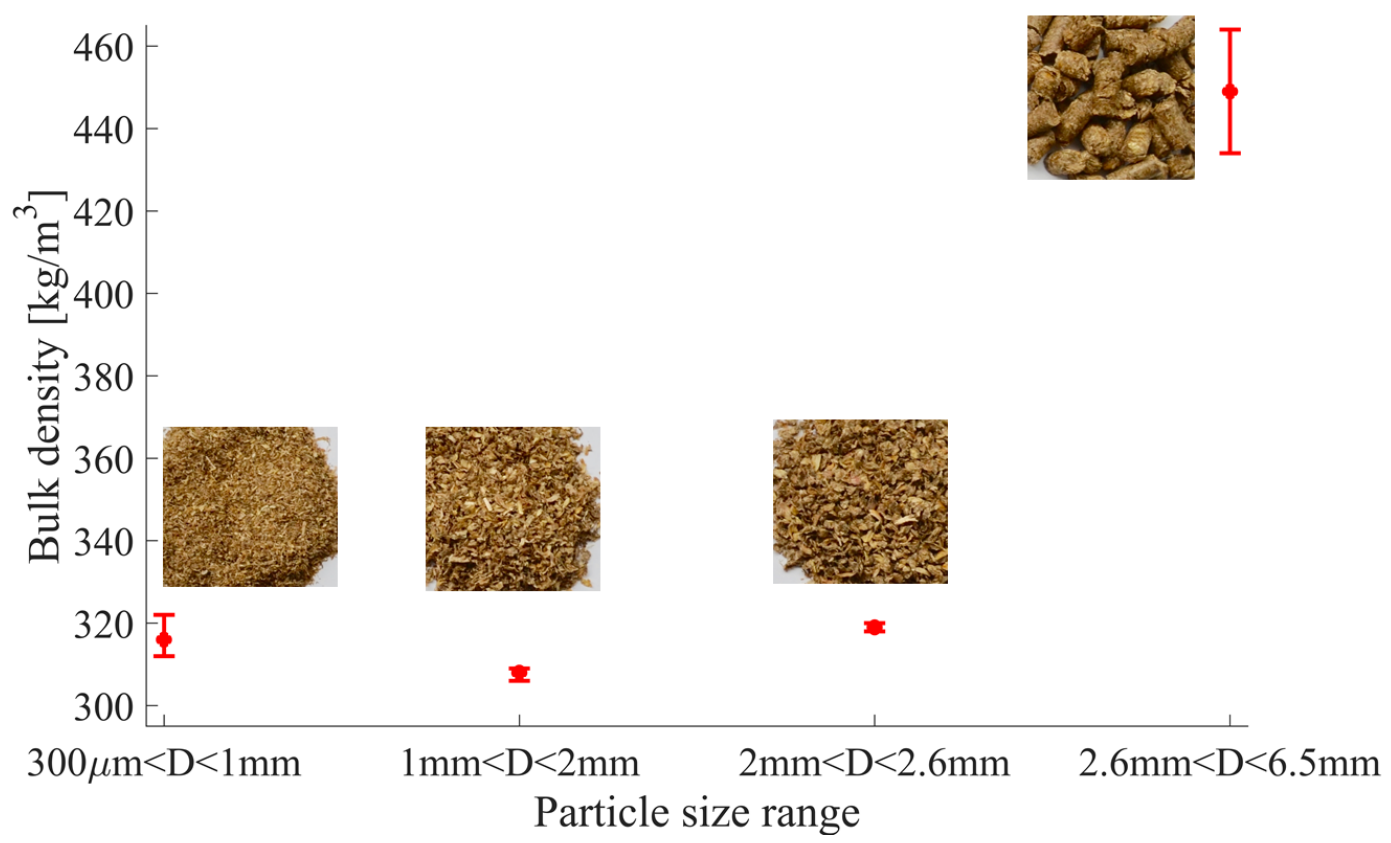

Figure 3: Density of the different sample size wheat biomass particles, ordered by increasing particle size.

\section{Results}

Given the same ambient reference temperature, different particles will ignite or not ignite from self-heating depending on the particle size. This is shown in Fig. 4, where given the same oven reference temperature of $183.7^{\circ} \mathrm{C}$ the finest particles, with particle size $300 \mu \mathrm{m}<\mathrm{D}<1 \mathrm{~mm}$ (dust size), shown by the red curve undergo thermal runaway and ignite while the coarse particles, with size $2.6 \mathrm{~mm}<\mathrm{D}<6.5 \mathrm{~mm}$, will not reach thermal runaway as can be seen by the black dashed curve in the figure.

Results from all the basket experiments are summarised in Fig. 5. The minimum ignition temperature required for ignition decreased with decreasing particle size for two of the basket volumes, but for all sizes is within the uncertainty bounds. This trend applied to all the 4 distributions studied, with the coarse sized particles $(2.6 \mathrm{~mm}<\mathrm{D}<6.5 \mathrm{~mm})$ and medium sized particles $(2 \mathrm{~mm}<\mathrm{D}<2.6 \mathrm{~mm})$ igniting from self-heating at the same temperatures. The pellet has higher density, as shown earlier in Fig. 3, so this increase in fuel present per given volume might be offsetting the effect of decreasing particle size. However, for fine particles $(1 \mathrm{~mm}<\mathrm{D}<2 \mathrm{~mm})$ there is a clear decrease in ignition temperature, and an even more significant drop in temperature required for ignition for the dust particle size distribution (300 $\mu \mathrm{m}$ $<\mathrm{D}<1 \mathrm{~mm}$ ). For this size distribution, the smallest being tested, at volumes of $442 \mathrm{~cm}^{3}$ there is a $6.3{ }^{\circ} \mathrm{C}$ difference in the minimum ignition temperature with respect to the $2.6 \mathrm{~mm}<\mathrm{D}<6.5 \mathrm{~mm}$ sized wheat pellets. This is the biggest temperature difference measured for the $442 \mathrm{~cm}^{3}$ basket. For the larger basket tested, ignition temperature differences 


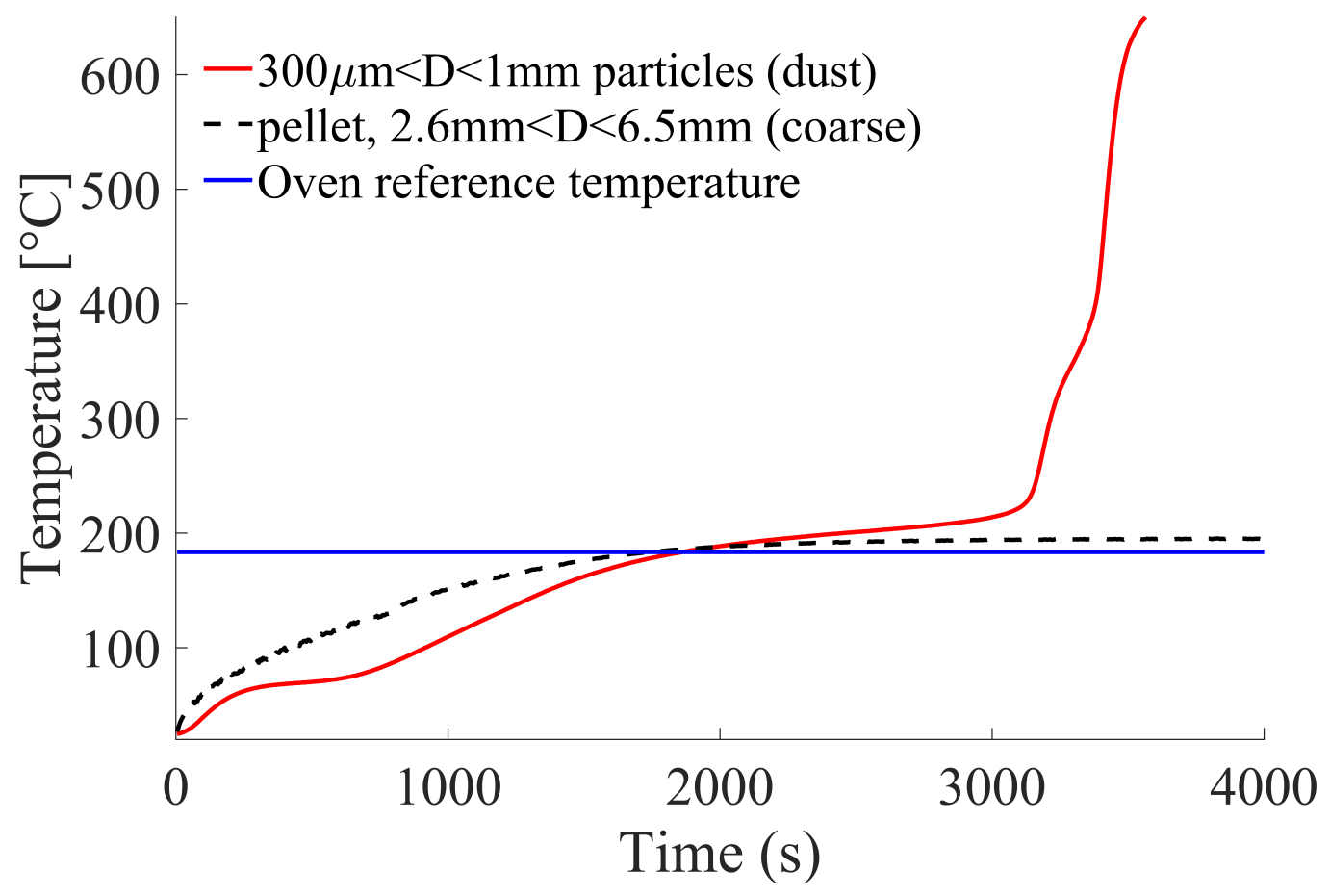

Figure 4: A comparison of ignition vs no ignition for two samples tested in $131 \mathrm{~cm}^{3}$ volume baskets made up of samples of different particle size distributions placed in the same oven environment of $183.7^{\circ} \mathrm{C}$. The basket with particles in the $300 \mu \mathrm{m}<\mathrm{D}<1 \mathrm{~mm}$ particle size range ignite due to self-heating, and is clear from the thermal runaway seen on the red line. The particles in the pellet size range $(2.6 \mathrm{~mm}<\mathrm{D}<6.5 \mathrm{~mm}) \mathrm{however}$ do not ignite, and no thermal runway is seen.

are much less pronounced, and lie within the experimental error cloud as seen by the black line in the figure so it is difficult to quantify size effects on the temperature data alone.

\section{Frank-Kamenetskii analysis}

The Frank-Kamenetskii theory of ignition criticality has been used extensively in the literature to investigate selfignition characteristics of materials, and to quantify thermal and kinetic properties from experimental bench-scale experiments $[6,24]$. The theory can also be used to upscale experimental results to predict self-ignition for larger sizes, if the mechanism of heat generation is unchanged $[6,24]$. The Frank-Kamenetskii theory of ignition assumes that the material is reactive and 1D, and that the heat release is in the form of a one-step exothermic reaction. For organic materials such as biomass there are two main sources of heat generation that make up this global reaction, a chemical process at higher temperatures and a biological process at lower temperatures [25]. Frank-Kamenetskii theory solves the heat transfer problem of heat conduction obtaining a dependence of critical sample size on ambient temperature which is expressed as Eq. (1)

$$
\ln \left(\frac{\delta_{c} T_{a, c}^{2}}{L^{2}}\right)=\ln \left(\frac{Q E f}{R k}\right)-\frac{E}{R T_{a, c}}
$$

where $\delta_{c}$ is the critical value of the Frank-Kamenetskii dimensionless parameter for which ignition occurs, which is a function of the geometrical shape of fuel, $E$ is the activation energy of the one-step global reaction, $k$ is the effective thermal conductivity of the biomass, $R$ is the universal gas constant, $L$ is the characteristic length of the sample (for a cube basket the side length), $Q$ is the heat of reaction per fuel mass, and $f$ is the value of the mass action law which relates the concentration of fuel and oxygen at the initial time to reaction rates, and is based on initial concentrations 


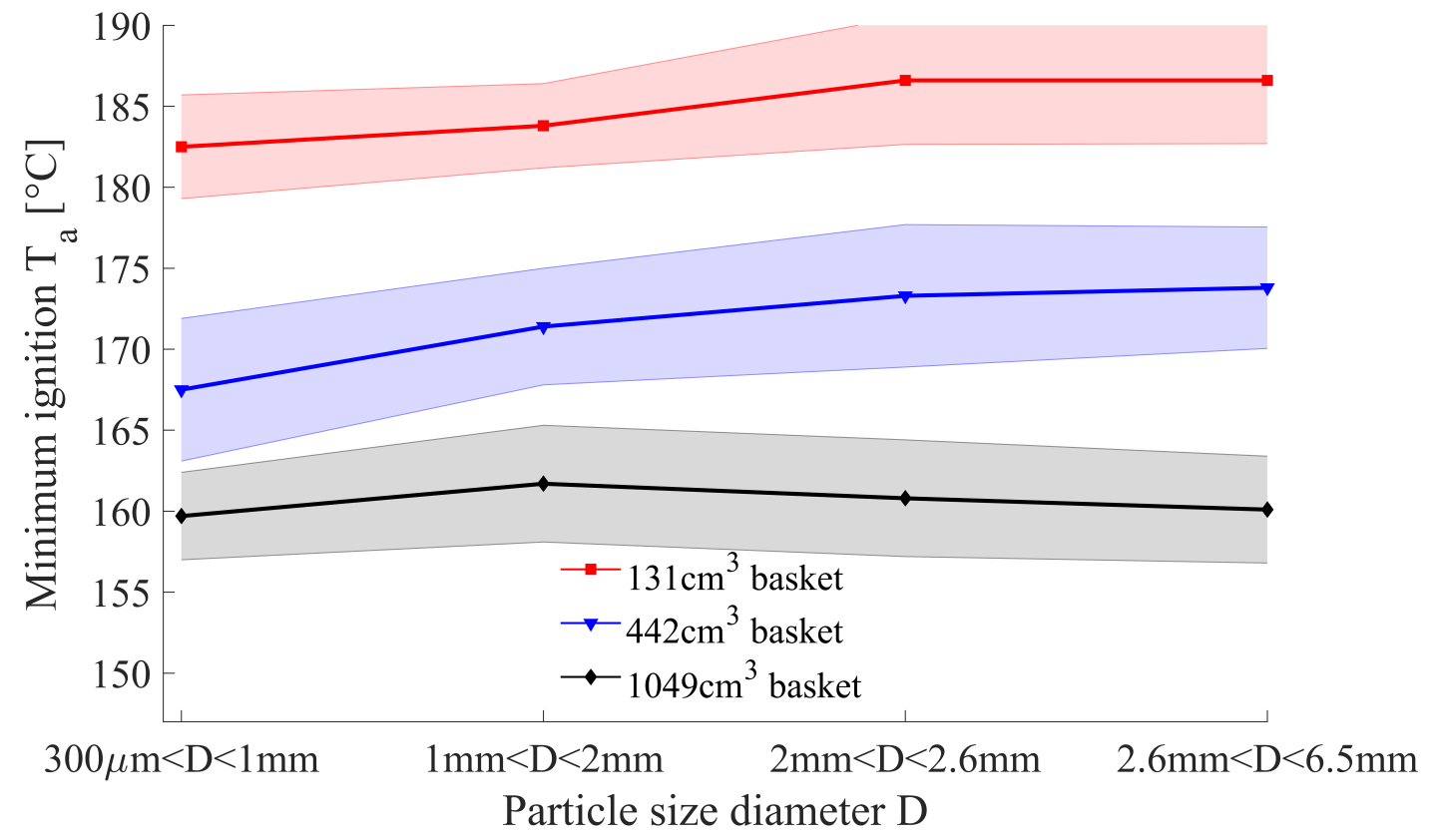

Figure 5: The experimentally found minimum ignition temperatures plotted with respect to the four studied particle size distributions, with separate lines for the three different box sizes. Error clouds include thermocouple sensitivity of $\pm 2^{\circ} \mathrm{C}$. The maximum temperature difference for the $131 \mathrm{~cm}^{3}$ basket volume is of $4.1^{\circ} \mathrm{C}$, for the $442 \mathrm{~cm}^{3}$ basket volume is of $6.3^{\circ} \mathrm{C}$, and for the $1049 \mathrm{~cm}^{3}$ basket volume is of $2.0^{\circ} \mathrm{C}$.

of fuel and oxygen [24]; $T_{a, c}$ is the critical (minimum) ambient temperature for which self-ignition occurs. $Q f$ can usually be lumped together to form a pre-exponential factor term, analogous to the one found for global reaction rates in gas-phase kinetics.

To use this theory, we plotted the critical ignition temperatures for the three basket volumes found for the experiments in all four particle size distributions tested in a $\ln \left(\delta_{c} T_{a, c} / L^{2}\right)$ vs $1 / T_{a, c}$ plot. The slope of the straight line through the critical ignition temperatures and sizes of different sized boxes, for the same particle size distribution, corresponds to $-E / R$; The y-intercept can be used to obtain $Q f$. The plot is shown in Fig. 6. From this figure, it can be seen that the pellets, $2.6 \mathrm{~mm}<\mathrm{D}<6.5 \mathrm{~mm}$, and the 2nd largest particles $(2 \mathrm{~mm}<\mathrm{D}<2.6 \mathrm{~mm})$ have almost identical slopes and almost overlap completely. The smallest particle sizes have a slightly higher tendency to ignite at lower temperature, but again fall in similar ranges. All four curves show the same trend, and for the largest box size all 4 particle size distributions show same ignition properties, as can be seen on the bottom right of Fig. 6 .

Effective activation energies and pre-exponential factors were extracted using the Frank-Kamenetskii theory and the experimental data, and are presented in Table 2. Although the upper and lower bounds for activation energies are large, due to the worst-case calculation of errors based on the upper and lower experimental bounds on each basket volume measurement from Fig. 6, several trends are observed. The slopes of all the particle size distributions are linear, with R-squared values of 0.985 or greater for all size distributions, confirming the validity of the Frank-Kamenetskii analysis approach. All four particle size distributions, have similar activation energies ranging between $93 \mathrm{~kJ} / \mathrm{mol}$ and $111 \mathrm{~kJ} / \mathrm{mol}$. The thermal and kinetic parameters were used to upscale the results to ambient temperatures typically found in the environment. Results for all particle sizes show that particles will ignite for piles between 11 and $30 \mathrm{~m}$ tall, depending on the particle size. Attention must be paid to dealing with storage of these particles, as although these heights are higher than what is found in domestic storage, they can be found in silo storage.

The thermal and kinetic parameters were used to upscale the results to ambient temperatures closer to what is typically found in the environment, between $10{ }^{\circ} \mathrm{C}$ and $40{ }^{\circ} \mathrm{C}$ for the four particle sizes studied in this experimental campaign and is shown in Fig. 7. Each line has an error bar for a sample temperature, based on the maximum error in upscaling of the experimental results. The results of the upscaling show similar behaviour for all four particle sizes, 


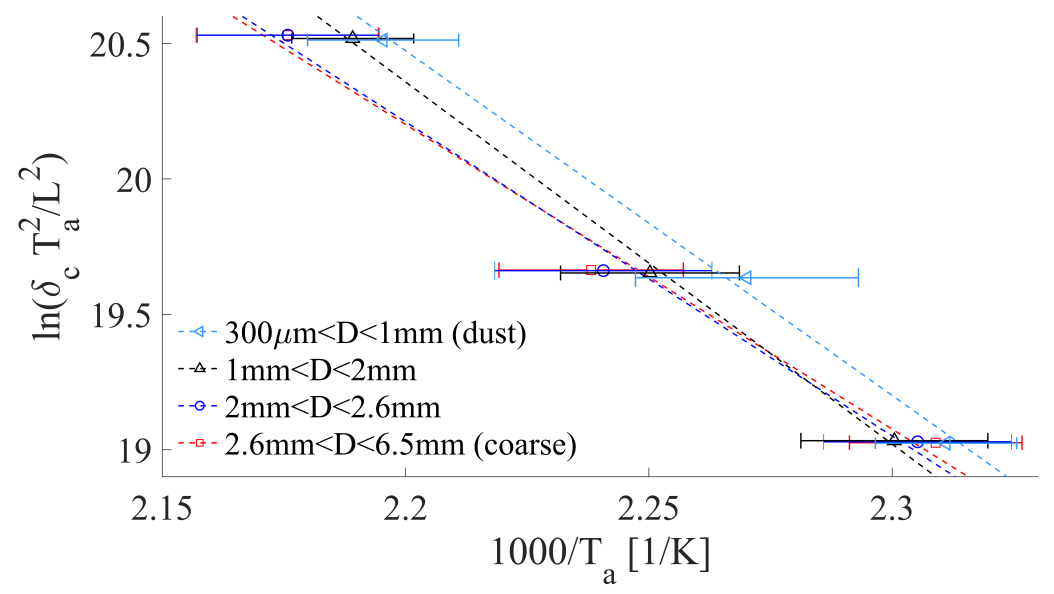

Figure 6: Frank-Kamenetskii plot of self-heating ignition properties for the four wheat biomass particle size distributions. R-squared values for each slope are provided in Table 2. Error bars in the y-direction are not presented as are neglible, less than $2 \%$.

Table 2: Effective activation energy $E$ and pre-exponential factors $Q f$ extracted from Frank-Kamenestkii plot (Fig. 6) calculated using Eq. (1). The values in parenthesis are lower and upper bounds values from uncertainty analysis, and the R-squared values of each slope to show linearity are presented for each particle size distribution

\begin{tabular}{lccc}
\hline $\begin{array}{l}\text { Particle size } \\
\text { distribution }\end{array}$ & $\begin{array}{c}E \\
(\mathrm{~kJ} / \mathrm{mol})\end{array}$ & $\begin{array}{l}\ln (Q f) \\
\left(W / m^{3}\right)\end{array}$ & $\begin{array}{c}R^{2} \\
(-)\end{array}$ \\
\hline $2.6 \mathrm{~mm}<\mathrm{D}<6.5 \mathrm{~mm}$ & $93.6(72.4,131.7)$ & $5.11 \cdot 10^{14}\left(2.30 \cdot 10^{12}, 1.13 \cdot 10^{19}\right)$ & 0.985 \\
$2 \mathrm{~mm}<\mathrm{D}<2.6 \mathrm{~mm}$ & $96.5(73.0,139.4)$ & $1.09 \cdot 10^{15}\left(2.66 \cdot 10^{12}, 8.27 \cdot 10^{19}\right)$ & 0.992 \\
$1 \mathrm{~mm}<\mathrm{D}<2 \mathrm{~mm}$ & $111.2(84.8,157.6)$ & $5.37 \cdot 10^{16}\left(5.95 \cdot 10^{13}, 9.81 \cdot 10^{21}\right)$ & 0.999 \\
$300 \mu \mathrm{m}<\mathrm{D}<1 \mathrm{~mm}$ & $105.9(83.6,146.8)$ & $1.54 \cdot 10^{16}\left(4.47 \cdot 10^{13}, 7.23 \cdot 10^{20}\right)$ & 0.996 \\
\hline
\end{tabular}

with the 2 coarser ranges being slightly more prone to self-heating ignition at ambient temperatures than the finer sized particles. For the particles between $1 \mathrm{~mm}<\mathrm{D}<2 \mathrm{~mm}$ the critical length required for self-heating ignition, at 40 ${ }^{\circ} \mathrm{C}$, is of $30 \mathrm{~m}$. For the pellet size particles, an $11 \mathrm{~m}$ tall pile would be required for self-heating ignition at the same temperature. Attention must be paid to dealing with storage of these pellets, as $11 \mathrm{~m}$ height is considerably higher than what is found in domestic storage areas, but can be found in situations like silo storage for example. This shows that for determining risk and propensity of self-ignition for biomass, particle size must be considered but does not bring very large changes in ignition conditions.

Each variable in this analysis carries uncertainty, and a complete uncertainty analysis is presented here. The bulk density differences within the measured particle sizes carry a maximum error of $7 \%$. The measurement of temperatures was carried out with K-type thermocouples, which have an accuracy of $\pm 2^{\circ} \mathrm{C}$. For that reason, the range of ignition was located within a minimum of $\pm 2.6^{\circ} \mathrm{C}$ and maximum of $\pm 4.4^{\circ} \mathrm{C}$ depending on the particle size. This temperature uncertainty then carries through to the calculation of effective activation energies and pre-exponential factors. Calculating these from the experiments for each particle size, based on upper and lower temperature limits, we have an uncertainty of up to $52 \%$ for the activation energy values, and up to $26 \%$ for pre-exponential factors. As the self-heating ignition temperatures found for the different particle sizes do not differ widely for a given pile size, when accounting for the uncertainty above no significant self-heating ignition differences can be found for the range of particle sizes studied. Recent work using hot-plate experiments has shown similar insensitivity of ignition behaviour to particle size for thick layers of biomass [26], so the findings from the isothermal basket experiments match the reactivity patterns found from other experimental techniques. 


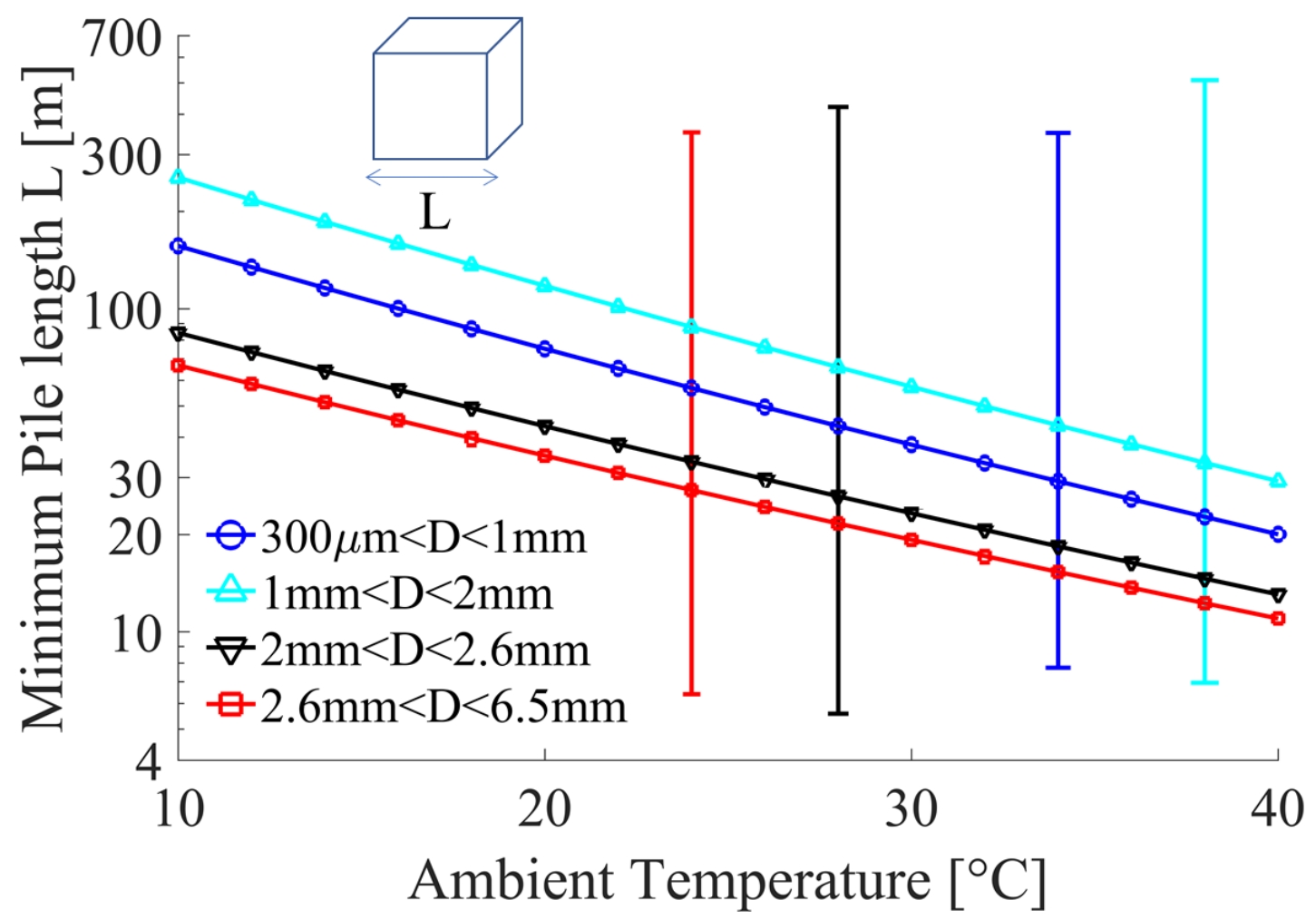

Figure 7: Upscaling the thermal properties and kinetics derived from the self-heating ignition basket experiments to larger scale sizes for the four particle size distributions. The upscaling is based on the parameters presented in Table 2. The error bars are given for 1 sample point for each curve, and represent the maximum error in upscaling of the experimental results.

\section{Conclusions}

Biomass for power use comes in bulk form, but can erode into smaller particle sizes, down to dust size below 500 $\mu \mathrm{m}$. Biomass is prone to self-heating ignition, and understanding the conditions required for it to ignite is fundamental. Extensive work exists on the study of different effects of particle size at the dust scale $\left(\mathrm{D}_{i} 500 \mu \mathrm{m}\right)$. However this paper is the first set of experimental work quantifying the effect from pellet diameter down to dust diameters. We investigate experimentally the effect using isothermal oven experiments. We show that for a given volume, the critical temperature for self-heating ignition marginally decreases with particle size, and that particle sizes have overall similar self-heating behaviour. In fact, particle size does not bring a significant effect on reactivity, with the finest particles in the size distribution between $300 \mu \mathrm{m}$ and $1 \mathrm{~mm}$ being slightly more reactive than the particles of diameter between $1 \mathrm{~mm}$ and $2 \mathrm{~mm}$ (a slightly smaller effective activation energy of $105.9 \mathrm{~kJ} / \mathrm{mol}$ compared to $111.2 \mathrm{~kJ} / \mathrm{mol}$ ). All of these activation energy values are within the experimental uncertainty, showing very small effect of particle size for the given basket volumes. In this work, we show that for particles of sizes between $300 \mu \mathrm{m}$ and pellet size self heating happens at similar critical temperatures and critical lengths. We show that as pile size increases, particle diameter effect becomes negligible. This is important when comparing to other fuels presented in literature where particle size is shown to be important at all pile sizes such as coal $[15,16]$, because this is not the case for biomass piles.

\section{Acknowledgments}

This research was funded by EPSRC (grant EP/L504786/1). The authors would like to thank Franz Richter (Imperial College London) for valuable discussions. 


\section{References}

[1] European Commission, Communication from the Commission, Europe 2020, Igarss 2014 (1) (2014) 1-5. arXiv:arXiv:1011.1669v3, doi:10.1007/s13398-014-0173-7.2.

[2] J. G. Torrent, L. O. J. M. Madariaga, Seguridad industrial en atmósferas explosivas, Laboratorio Oficial José María Madariaga, 2003.

[3] V. Ganesan, K. A. Rosentrater, K. Muthukumarappan, Flowability and handling characteristics of bulk solids and powders - a review with implications for DDGS, Biosystems Engineering 101 (4) (2008) 425-435. doi:10.1016/j.biosystemseng.2008.09.008. URL http: //dx.doi.org/10.1016/j.biosystemseng. 2008.09.008

[4] H. Kurz, G. Münz, The influence of particle size distribution on the flow properties of limestone powders, Powder Technology 11 (1) (1975) 37-40. doi:10.1016/0032-5910(75)80020-9.

URL http://www.sciencedirect.com/science/article/pii/0032591075800209

[5] P. Bowes, Self-Heating: Evaluating and Controlling the Hazards, HMSO, London, 1984.

[6] D. Drysdale, An Introduction to Fire Dynamics, 3rd Edition, Wiley and Sons, Chichester, 2011. doi:10.1002/9781119975465.

[7] J. García-Torrent, A. Ramírez-Gómez, E. Querol-Aragón, C. Grima-Olmedo, L. Medic-Pejic, Determination of the risk of self-ignition of coals and biomass materials, Journal of Hazardous Materials 213-214 (2012) 230-235. doi:10.1016/j.jhazmat.2012.01.086. URL http://dx.doi.org/10.1016/j.jhazmat.2012.01.086

[8] J. M. Jones, A. Saddawi, B. Dooley, E. J. S. Mitchell, J. Werner, D. J. Waldron, S. Weatherstone, A. Williams, Low temperature ignition of biomass, Fuel Processing Technology 134 (2015) 372-377. doi:10.1016/j.fuproc.2015.02.019.

URL http://dx.doi.org/10.1016/j.fuproc.2015.02.019

[9] K. Rupar-Gadd, J. Forss, Self-heating properties of softwood samples investigated by using isothermal calorimetry, Biomass and Bioenergy (2017) 4-10doi:10.1016/j.biombioe.2017.04.008. URL http://linkinghub.elsevier.com/retrieve/pii/S0961953417301642

[10] Q. Luo, D. Liang, H. Shen, Evaluation of self-heating and spontaneous combustion risk of biomass and fishmeal with thermal analysis (DSC-TG) and self-heating substances test experiments, Thermochimica Acta 635 (2016) 1-7. doi:10.1016/j.tca.2016.04.017.

[11] F. Restuccia, N. Ptak, G. Rein, Self-heating behavior and ignition of shale rock, Combustion and Flame 176 (2017) $213-219$. doi:10.1016/j.combustflame.2016.09.025.

[12] F. Restuccia, X. Huang, G. Rein, Self-ignition of natural fuels: Can wildfires of carbon-rich soil start by self-heating?, Fire Safety Journal 91 (Supplement C) (2017) 828-834, fire Safety Science: Proceedings of the 12th International Symposium. doi:10.1016/j.firesaf.2017.03.052. URL http: //dx.doi.org/10.1016/j.firesaf .2017.03.052

[13] F. Restuccia, O. Mašek, R. M. Hadden, G. Rein, Quantifying self-heating ignition of biochar as a function of feedstock and the pyrolysis reactor temperature, Fuel 236 (2019) 201-213. doi:https://doi.org/10.1016/j.fuel.2018.08.141.

[14] N. Fernandez-Anez, J. Garcia-Torrent, L. Medic-Pejic, Flammability properties of thermally dried sewage sludge, Fuel 134 (2014) 636-643. doi:10.1016/j.fuel.2014.06.006.

URL http://dx.doi.org/10.1016/j.fuel.2014.06.006

[15] F. Akgun, A. Arisoy, Effect of particle size on the spontaneous heating of a coal stockpile, Combustion and Flame 99 (1) (1994) 137-146. doi:10.1016/0010-2180(94)90085-X.

[16] Y. S. Nugroho, A. C. McIntosh, B. M. Gibbs, Low-temperature oxidation of single and blended coals, Fuel 79 (15) (2000) $1951-1961$. doi:10.1016/S0016-2361(00)00053-3.

[17] A. Ramirez, J. Garcia-Torrent, A. Tascon, Experimental determination of self-heating and self-ignition risks associated with the dusts of agricultural materials commonly stored in silos, Journal of Hazardous Materials 175 (1-3) (2010) 920-927. doi:10.1016/j.jhazmat.2009.10.096.

[18] J. Garcia Torrent, N. Fernandez Anez, L. Medic Pejic, L. Montenegro Mateos, Assessment of self-ignition risks of solid biofuels by thermal analysis, Fuel 143 (2015) 484-491. doi:10.1016/j.fuel.2014.11.074. URL http://dx.doi.org/10.1016/j.fuel.2014.11.074

[19] K. Palmer, P. Tonkin, The ignition of dust layers on a hot surface, Combustion and Flame 1 (1) (1957) 14-18.

[20] G. Leuschke, Experimental investigations on self-ignition of dust deposits in hot environments (68) (1981) 1-9.

[21] W. Hensel, U. Krause, W. John, K. Machnow, Critical parameters for the ignition of dust layers at constant heat flux boundary conditions, Process Safety Progress 13 (4) (1994) 210-213.

[22] V. Babrauskas, Ignition Handbook, Fire Science Publishers, 2003.

[23] F. Áñez, M. de las Nieves, Analysis of the flammability properties of solid fuels, Ph.D. thesis, ETSI_Energia (2016).

[24] B. Gray, in: SFPE Handbook of Fire Protection Engineering, 4th Edition, 2008, Ch. 2-10: Spontaneous combustion and self-heating, pp. 241-258.

[25] M. I. Nelson, T. R. Marchant, G. C. Wake, E. Balakrishnan, X. D. Chen, Self-heating in compost piles due to biological effects, Chemical Engineering Science 62 (17) (2007) 4612-4619. doi:10.1016/j.ces.2007.05.018.

[26] N. Fernandez-Anez, J. Garcia-Torrent, Influence of particle size and density on the hot surface ignition of solid fuel layers, Fire Technology (2018) 1-17. 